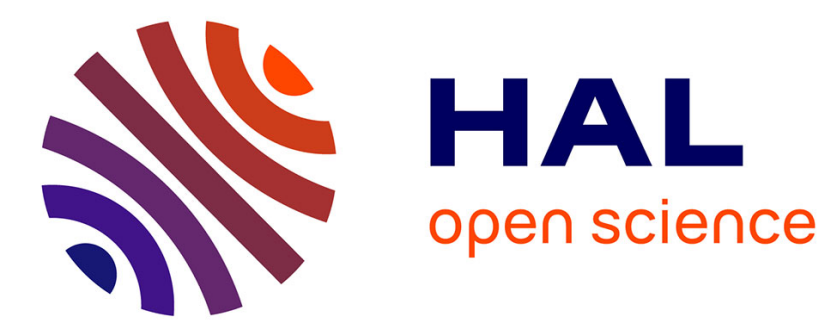

\title{
Bypassing nonadherence via PEG in a critically ill HIV-1-infected patient
}

Jan Leipe, Axel J Hueber, Juergen Rech, Thomas Harrer

\section{To cite this version:}

Jan Leipe, Axel J Hueber, Juergen Rech, Thomas Harrer. Bypassing nonadherence via PEG in a critically ill HIV-1-infected patient. AIDS Care, 2008, 20 (07), pp.863-867. 10.1080/09540120701767182 . hal-00513439

\section{HAL Id: hal-00513439 \\ https://hal.science/hal-00513439}

Submitted on 1 Sep 2010

HAL is a multi-disciplinary open access archive for the deposit and dissemination of scientific research documents, whether they are published or not. The documents may come from teaching and research institutions in France or abroad, or from public or private research centers.
L'archive ouverte pluridisciplinaire HAL, est destinée au dépôt et à la diffusion de documents scientifiques de niveau recherche, publiés ou non, émanant des établissements d'enseignement et de recherche français ou étrangers, des laboratoires publics ou privés. 

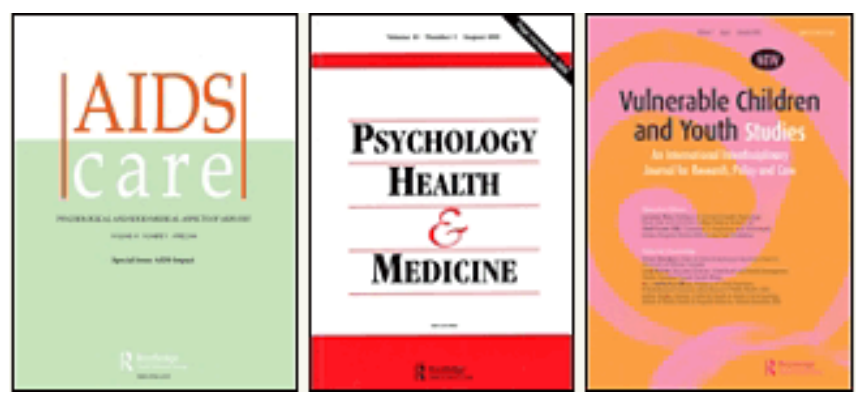

\section{Bypassing nonadherence via PEG in a critically ill HIV-1- infected patient}

\begin{tabular}{|r|l|}
\hline Journal: & $\begin{array}{l}\text { AIDS Care - Psychology, Health \& Medicine - Vulnerable Children } \\
\text { and Youth Studies }\end{array}$ \\
\hline Manuscript ID: & AC-2007-05-0200.R1 \\
\hline Journal Selection: & AIDS Care \\
\hline Keywords: & $\begin{array}{l}\text { nonadherence, medication adherence, HIV infection, } \\
\text { toxoplasmosis, PEG }\end{array}$ \\
\hline
\end{tabular}

\section{(1) ScholaroNE \\ Manuscript Central}


Bypassing nonadherence via PEG in a critically ill HIV-1-infected patient

Keywords: nonadherence, medication adherence, HIV infection, toxoplasmosis, PEG

Running head: PEG for nonadherence in HIV-infection 


\section{Abstract}

We report on a non-compliant 44-year-old HIV-1-infected male patient who presented with life threatening toxoplasmic encephalitis (TE). The case demonstrates life saving and long term benefit of percutaneous endoscopic gastrostomy (PEG) for the treatment of a HIV-1 infected patient with psychological inability to swallow drugs and recurrent, serious opportunistic infections.

Comment [j1]: alternative abstract

This case study describes a 44-year-old chronically non-adherent HIV-infected male with relapsing, $\underline{\text { life }}-\mathcal{P}$ tening toxoplasmic encephalitis (TE) and other recurring opportunistic infections. Nonadh $\equiv$; resulted in critical illness, suppressed CD4 lymphocyte count and elevated viral load. In order to bypass the patient's complete psychological aversion to taking medication, and after exhausting various psychological interventions, a percutaneous endoscopic gastronomy (PEG) tube was inserted for delivery of indispensable medication. During the 15 month follow-up, the patient was adherent, exhibiting a consistently undetectable viral load, high CD4 count and a remission of the opportunistic infections. This is an interesting case study demonstrating life-saving and long-term benefit of PEG in an exceptional setting, which has implications for future research and treatment of non-adherent HIV-infected patients. 
Introduction Antiretroviral therapy (ART) has markedly reduced AIDS-related mortality and morbidity with a decline in the rates of hospitalization and opportunistic infections associated with HIV-1 infection. ${ }^{1,2}$ The most important factor for a long-term success of ART is the continuous reduction of HIV-1 viremia below the limit of the current detection assays, usually below 50 copies/ml. However, failure to adhere to ART rapidly selects genetic variants with decreased drug susceptibility resulting in loss of viral control and, ultimately, in progressive immunodeficiency. Hence, adherence to the prescribed regimen is essential for successful treatment and therefore has been termed the 'Achilles heel of antiretroviral therapy'. ${ }^{3}$ Of note, in patients with $95 \%$ or greater adherence, virologic failure was found in only $22 \%$, no new opportunistic infections or deaths occurred and they spent fewer days in the hospital. ${ }^{4}$ Unfortunately, despite the importance of strict compliance, it is estimated that 18 to $54 \%$ of HIV-positive individuals are nonadherent to ART. Estimation of patients' adherence in studies included different methods. Besides electronic monitoring, pill counts and refill history which are complex, time consuming and impractical for most clinical settings, self-reported adherence although an indirect measure is simple and predicts important virological and immunological outcomes. ${ }^{7}$

For patients with advanced HIV-1 infection where malnutrition is an important cause of morbidity and mortality, percutaneous endoscopic gastrostomy (PEG) tube has been shown to be a safe and effective method of providing nutrition in patients who are unable to swallow food. ${ }^{8}$ Moreover, PEG enables a long-term nutritional support improving quality of life in those patients. ${ }^{9}$ Here, we describe the case of a patient with advanced HIV infection and a life threatening relapsing TE who was not able to take antiretroviral drugs and antibiotics due to a psychological blockade to swallow tablets. Delivery of indispensable drugs via PEG tube resulted in long-term improvement of both infections with an ultimate clinical stabilisation.

\section{Case report}

In May 2005, the 44-year-old HIV-infected Caucasian male patient presented with a transient dysarthria, left sided central facial paralysis, right sided palsy and hypaesthesia. Magnetic resonance imaging (MRI) revealed a solitary mass lesion in the left fronto-parietal lobe with typical contrast enhancement strongly suggesting central nervous system toxoplasmosis. Laboratory analysis showed a low CD4 lymphocyte count of 18/ $\mu$ l, and a high plasma viral load of $130.000 \mathrm{HIV}$ - 
RNA copies/ml. The patient was diagnosed with HIV-1 infection in 1993, and since 1993 he has been on various ART. Due to side effects to several drugs such as efavirenz and various protease inhibitors, it was necessary to modify the ART regimens several times. Since the start of therapy, his viral load could never be suppressed and his CD4 counts remained below 40 cells per microliter. Although the patient denied generally missing medication in the past it was suspected that the lack of response to ART might be secondary to a poor adherence to his medication, because HIV-1 resistance testing consistently confirmed viral susceptibility to the majority of prescribed drugs. A phenotypic resistance test, performed two years earlier, showed resistance to 3TC and to all NNRTIs, but susceptibility to all available PIs and all other NRTIs. At admission, the patient reported that he had stopped his antiretroviral medication four months ago because of abdominal discomfort. Anti-Toxoplasma treatment was started with pyrimethamine at $100 \mathrm{mg}$ per os (p.o.) and intravenous (i.v.) clindamycin $600 \mathrm{mg}$ q.i.d. with subsequent clinical and radiological improvement. The neurological symptoms disappeared and the cerebral lesion significantly diminished (Fig.1A, B). A concomitant CMV gastritis and oropharyngeal candidiasis was successfully treated with foscarnet and i.v. fluconazole. Because of the long treatment history with antiretrovirals and the results of previous resistance tests we initiated a broad antiretroviral combination regimen including nelfinavir, tenofovir, zidovudine, lamivudine and abacavir. Nelfinavir was chosen because of his aversion to ritonavir and lopinavir/r. Due to his difficulties with swallowing oral drugs he received liquid formulations of abacavir, zidovudine and lamivudine. At discharge, three weeks later the viral load was markedly decreased to 170 copies $/ \mathrm{ml}$. As the results of the genotypic resistance analysis indicated only intermediate sensitivities to nelfinavir, lopinavir and atazanavir, we switched nelfinavir to ritonavir and boosted fosamprenavir that displayed full genotypic activity. During the following weeks he showed rising viral loads (22 000 copies $/ \mathrm{ml}$ ), presumably due to low compliance as serum levels of amprenavir were below the detection limit of the assay. As he indicated difficulties with swallowing ritonavir capsules we prescribed liquid ritonavir and stressed the importance of compliance. Five months later, he was rehospitalized in critically ill condition with a left sided central facial palsy, headache, fatigue, herpes labialis and oral thrush. MRI showed a new large active cerebral mass as well as multiple other lesions consistent with cerebral toxoplasmosis (Fig. 1C). As the patient insisted on a good adherence to his medication including oral anti-Toxoplasma therapy, a brain biopsy was performed which excluded lymphoma and a relapsing toxoplasmosis was proven by PCR. He showed a high plasma viral load with 160.000 HIV-RNA copies/ml (Fig. 2). Genotypic resistance analysis showed full sensitivity to all then available RT-inhibitors and protease inhibitors (including amprenavir) except for an only intermediate sensitivity to atazanavir. As the amprenavir concentration was again below the detection limit, reduced adherence rather than altered absorption or elimination was suspected as the cause of low drug concentrations. Only after repeated questioning, the patient admitted to a complete psychological inability of self-application of oral and subcutaneous antiretroviral and antimicrobial treatment.
Deleted: Due to his difficulties to swallow

Deleted: $y$

Deleted: to swallow

Deleted: p.o

Deleted: A

Deleted: Potential barriers to adherence were addressed and he received again intensive counselling about treatment and consequences of non-adherence. 
$\underline{\text { In accordance with the patient, a multidisciplinary care team including the medical staff, nurses, and }}$ psychologists created a patient-tailored approach by combining several psychological interventions in order to overcome his medication nonadherence. As a part of the educational interventions the patient was provided with information on HIV therapy. He also received individualized education about the importance of adherence in a context to increase intrinsic motivation for change by addressing potential strategies aiming to support adherence to medication. Further, cognitive behavioural stress management was tried to reduce stress and decrease depressed mood. Guided by a psychologist, the patient was taught a variety of relaxation exercises, including progressive muscle relaxation, autogenic training and meditation. He was encouraged to examine potentially distorted cognitions and negative perceptions of medication intake, and how these may influence his adherence. The larger $\underline{\text { stressor of adherence should be broken down into smaller, more manageable components and then }}$ matched to a productive coping response. Together with the patient we made efforts to optimize social support from the partner and family. We instructed his partner to assist with and help take responsibility for the patient's medication-taking and adherence.

Despite all these educational, behavioural and social interventions, he was not able to overcome his severe aversion to oral intake of drugs, also to drug combinations, which he could tolerate without side effects. Of note, the patient had normal intake of food. Therefore, given the critical situation with progressive immunodeficiency and recurrent toxoplasma encephalitis, various interventions being exhausted, a PEG tube for administration of medication was placed endoscopically without complications with the patient's consent. The procedure was performed with conscious sedation using intravenous midazolam and pethidine. After identification of the optimal puncture site, a $20 \mathrm{~F}$ tube (Fresenius Kabi, Bad Homburg, Germany) was endoscopically placed using the standard pull technique.

Given that the procedure is not routinely performed in this setting, pros and cons of practical and ethical aspects were extensively discussed with the patient aspects such as the risks associated with the procedure itself and possible consequences like wound healing problems. On the other hand, the low complication rate of this common procedure, the benefit from PEG placement as a means to provide oral medications at home, and given a regular administration, the possibility to control HIV and other infections were discussed. Although PEG placement is not routinely performed in such situations, together with the patient, we considered it is as a chance to manage this critical situation. Moreover, we conferred with the patient, that the PEG was not intended to be permanent, since as soon as the patient would overcome his inability while receiving further support to accomplish that, the PEG tube would be removed.

The ART via PEG was continued with liquid formulations of lopinavir, low-dose ritonavir, abacavir, tenofovir and lamivudine In addition, his partner was instructed to apply enfuvirtide subcutaneously. For the toxoplasma treatment we applied orally pyrimethamine and clindamycin in combination with
Deleted: Even so, and despite intensive psychological support, also by trained psychologists

Deleted: even

Deleted: before

Deleted: 
the application of liquid atovaquone via his PEG tube. This approach led to a significant reduction in Toxoplasma lesions (Fig. 1 C, D), a sustained decrease in HIV-RNA copies and an increase in CD4 counts during the following months (Fig. 2). Over a follow up of 15 months the patient remained asymptomatic without relapse of the toxoplasma encephalitis and his viral load was continuously suppressed to less than 50 copies per milliliter. He used his PEG for the whole period of 15 months, as all efforts to take oral medication failed so far despite intensive medial and psychological support. Only recently, while being on constant psychological therapy, he made a new attempt to switch to an oral medication.

\section{Discussion}

We describe a male, non-adherent patient with advanced HIV infection presenting with life threatening relapsing toxoplasmic encephalitis in whom application of indispensable drugs via a PEG tube resulted in the successful control of his HIV-1 and Toxoplasma infections.

The patient admitted to have certain problems to take specific drugs especially protease inhibitors consisting of large capsules, but he insisted on overall good compliance with regular intake of the drugs in the face of evidence to the opposite. The denial of his non-compliance occurred despite efforts and interventions described above to decrease side effects and to improve tolerability of drug. An important reason for this denial, as the patient told us, was the fear to disappoint his partner, family and the medical team by confessing his "weakness" in following the medical recommendations. Denial and adherence difficulties are not rare in severely ill patients and they have been reported in patients with advanced HIV-1 infection. Unfortunately, strategies to identify these patients have not been defined yet. ${ }^{10}$ An important indicator of non-compliance is the presence of a high HIV-1 viremia without the presence of drug resistance mutations. It has been suggested that virologic failure may occur even without the development of known drug resistance mutations, however, these rare cases seem to originate mainly from pharmacological problems such as low serum or intracellular drug levels and less from yet unknown resistance mechanisms. Determination of drug serum levels allows the control of drug intake; however it can be confounded by restarting drug intake
Deleted: A, B

\section{Deleted: is}

Deleted: compassionate care and active support

Deleted: environment

Deleted: and to

Deleted: to

Deleted: or 
just before the outpatient visits. Thus, measurements of serum levels should be performed repeatedly when suspecting non-compliance.

We assume, that, in the beginning, his compliance problems were triggered by previous experiences of drug-related side effects inducing a severe aversion to oral drugs. Initially, this aversion to drugs may

Deleted: Consistent with these findings, modified directly observed therapy was described to enhance adherence in difficult-to-treat patients, but improvements decreased with time. ${ }^{11,12}$ Deleted: , have been augmented by the discomfort due to the encephalitis and the gastrointestinal CMV infection. However, this psychological barrier continued, even after improvment of the opportunistic infections and the initiation of drug combinations that were well tolerated by the patient. Similar psychological blockades have been observed also in cancer patients experiencing strong side effects especially after emetogenic cytostatic therapy. This case underlines once more the necessity of a proactive management of side effects of drugs to avoid the development of negative psychological barriers that could jeopardize future therapy.

After the patient at last conceded his nonadherence, efforts to improve adherence were increased by employing psychological care. Although he reported on a certain benefit from this approach, intensive psychologic treatment did not lead to improvement of his psychological inability. As the patient was suffering from the life threatening toxoplasmic encephalitis we tried to overcome his severe aversion by the placement of a PEG tube, despite the potential risks of wound infection as common complications in those patients. ${ }^{8}$ Finally, this procedure proved to be highly successful with subsequent control of his HIV-1 infection and the severe encephalitis. Over a time of 15 months patient still uses his PEG tube without local infection or other complications.

In summary, this unique case demonstrates the life saving value of a PEG in the clinical management of patients having problems with the oral self-application of medication. To our knowledge, within the field of antiretroviral therapy, this is the first description of a clinical management using a PEG tube for administration of medication in the setting of a mainly psychologically induced noncompliance during a critical opportunistic infection. 


\section{References}

1. Palella FJ, Jr, Delaney KM, Moorman AC, et al. (1998). Declining morbidity and mortality among patients with advanced human immunodeficiency virus infection. HIV outpatient study investigators. New England Journal of Medicine; 338:853-860.

2. Hogg RS, Heath KV, Yip B, et al. (1998). Improved survival among HIV-infected individuals following initiation of antiretroviral therapy. Journal of the American Medical Association; 279:450-454.

3. Sherr L. (2000). Understanding adherence. Journal of HIV therapy; 5:30-5.

4. Paterson DL, Swindells S, Mohr J, et al. (2000). Adherence to protease inhibitor therapy and outcomes in patients with HIV infection. Annals of Internal Medicine; 133:21-30.

5. Catz SL, Kelly JA, Bogart LM, et al. (2000). Patterns, correlates, and barriers to medication adherence among persons prescribed new treatments for HIV disease. Health Psychology; $19: 124-133$.

6. Tesoriero J, French T, Weiss L, et al. (2003). Stability of adherence to highly active antiretroviral therapy over time among clients enrolled in the treatment adherence demonstration project. Journal of Acquired Immune Deficiency Syndromes; 33:484-493.

7. Haubrich RH, Little SJ, Currier JS, et al. (1999). The value of patient-reported adherence to antiretroviral therapy in predicting virologic and immunologic response. California Collaborative Treatment Group. AIDS; 13:1099-1107.

8. Crotty B, McDonald J, Mijch AM, Smallwood RA. (1998). Percutaneous endoscopic gastrostomy feeding in AIDS. Journal of Gastroenterology and Hepatology; 13(4):371-5.

9. Cappell MS, Godil A. (1993). A multicenter case-controlled study of percutaneous endoscopic gastrostomy in HIV-seropositive patients. American Journal of Gastroenterology.; 88(12):205966.

10. Miller LG and Chang ES. (2002). Human immunodeficiency virus infection unresponsive to highly active antiretroviral therapy: Denial of poor medication adherence or recalcitrant infection? AIDS Patient Care STDs; 16:355-359.

$$
\mid
$$

Deleted: 11. Stenzel MS, McKenzie M, Mitty JA, et al. (2001). Enhancing adherence to HAART: A pilot program of modified directly observed therapy. The AIDS reader; $11: 317-328$.II 12. Lucas GM, Flexner CW, Moore RD. (2002). Directly administered antiretroviral therapy in the treatment of HIV infection: Benefit or burden? AIDS Patient Care STDs; 16:527-535. 


\section{Figure legends}

Figure 1. Decline of cerebral lesions under therapy. (A) MRI at $1^{\text {st }}$ admission showing a lesion in the left fronto-parietal lobe with contrast enhancement. (B) After two weeks of therapy, the lesion has markedly decreased. (C) MRI at $2^{\text {nd }}$ admission revealing an enhancing mass lesion right frontoparietal associated with marked perifocal edema. (D) 6 months after $2^{\text {nd }}$ admission, on prophylaxis with pyrimethamine and clindamycin administered via PEG.

Figure 2. Course of plasma viral load indicated as HIV-RNA copies/ml and CD4 lymphocyte counts presented as cells/ $\mu$ l. Arrow: placement of PEG tube. 
Figure 1.

A

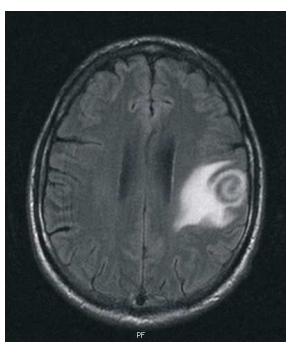

C

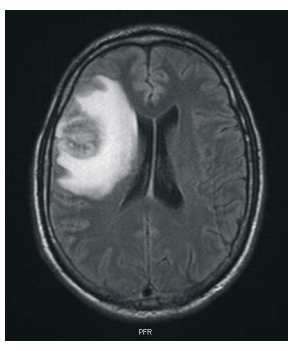

B

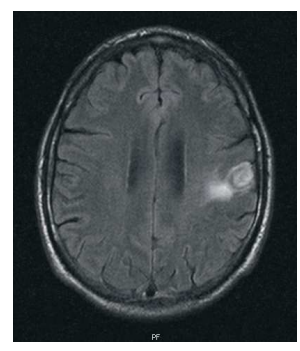

D

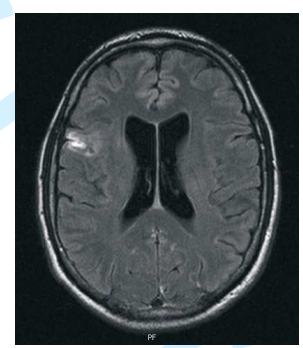


Figure 2.

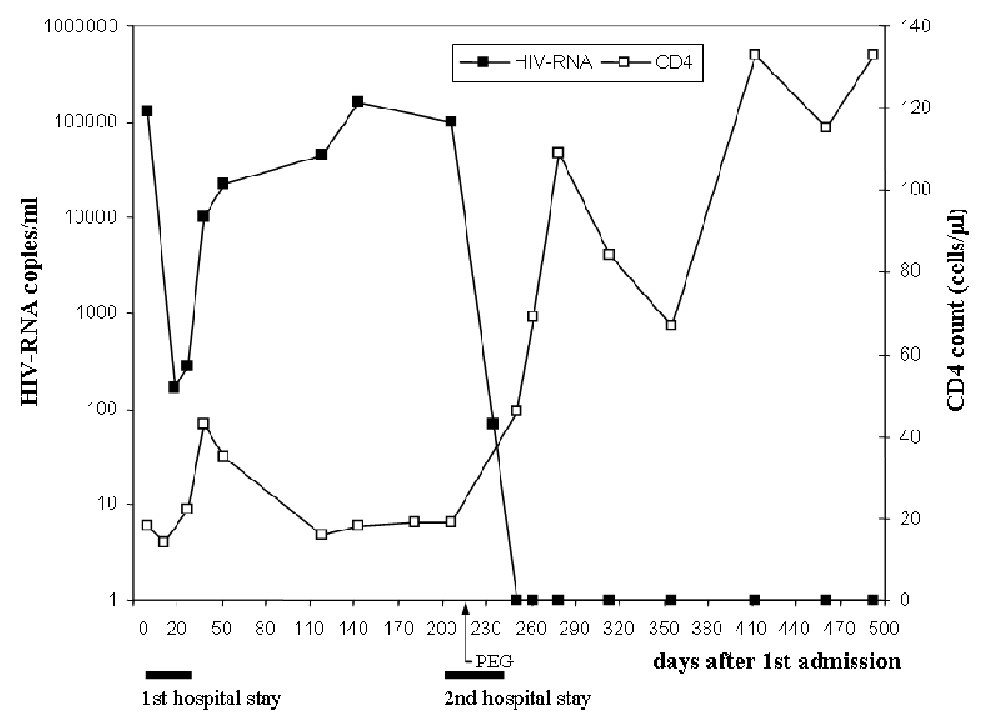




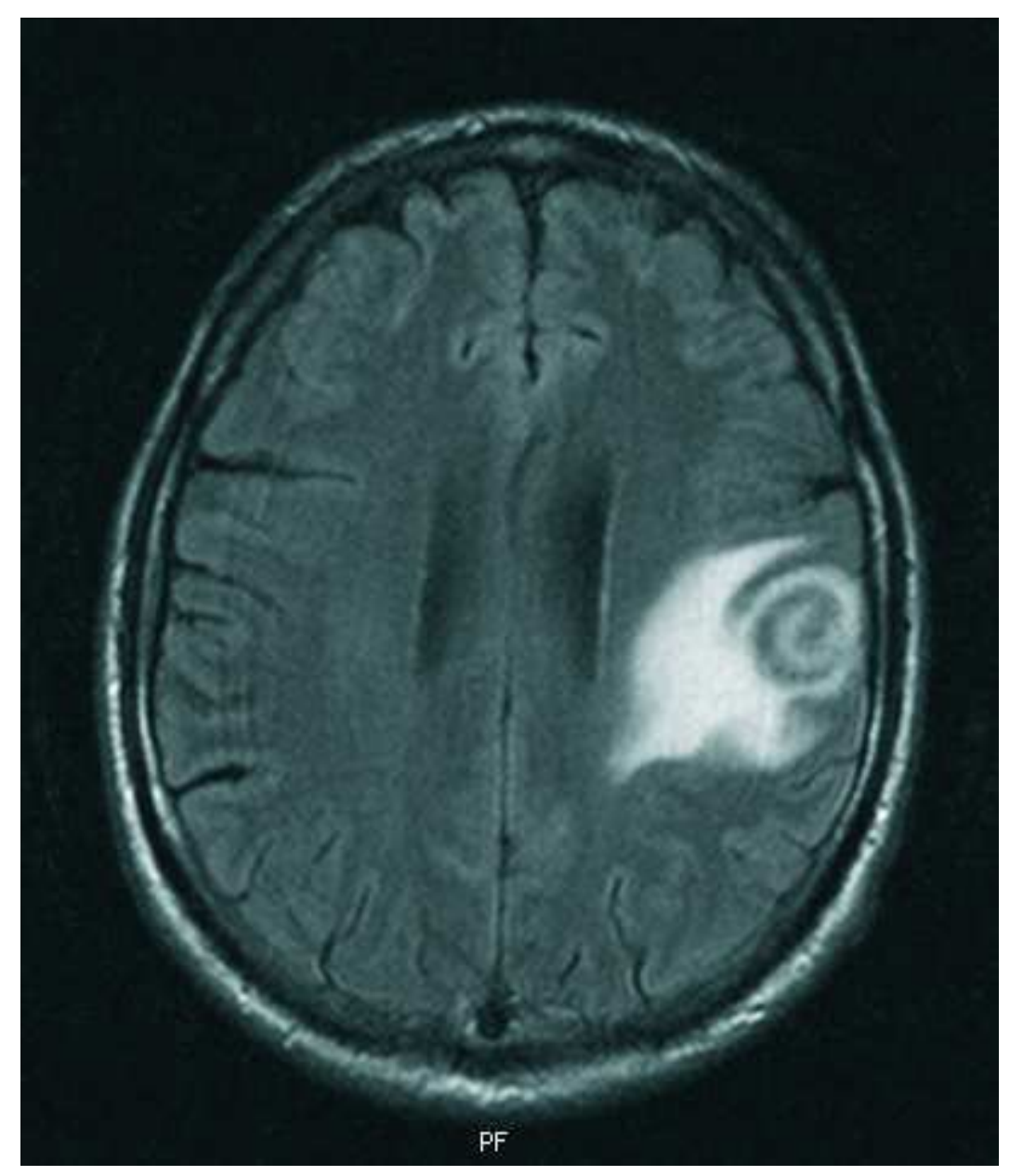

Fig. $1 \mathrm{~A}$

$34 \times 40 \mathrm{~mm}(300 \times 300$ DPI $)$ 


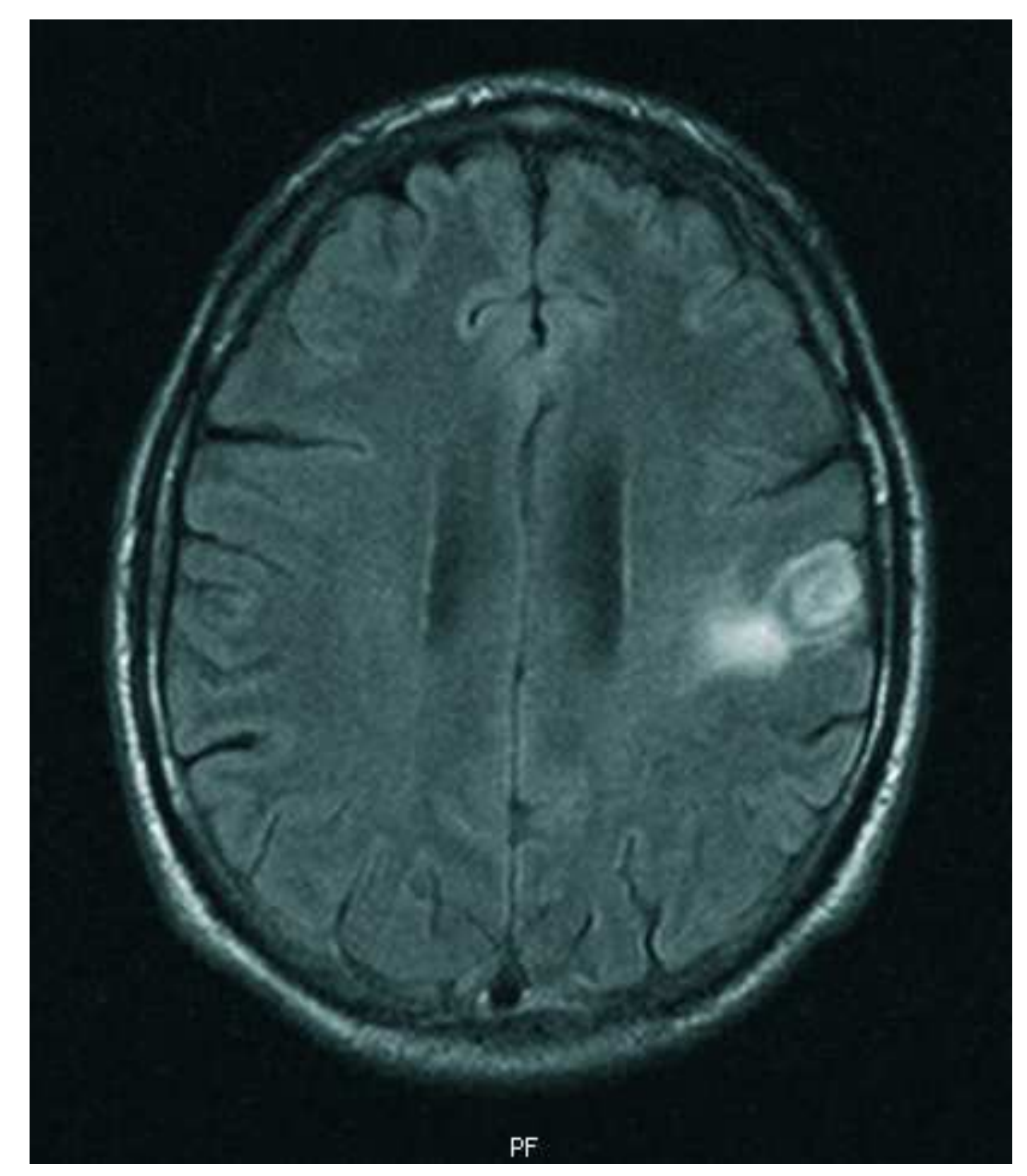

Fig. 1B

$34 \times 40 \mathrm{~mm}(300 \times 300$ DPI $)$ 


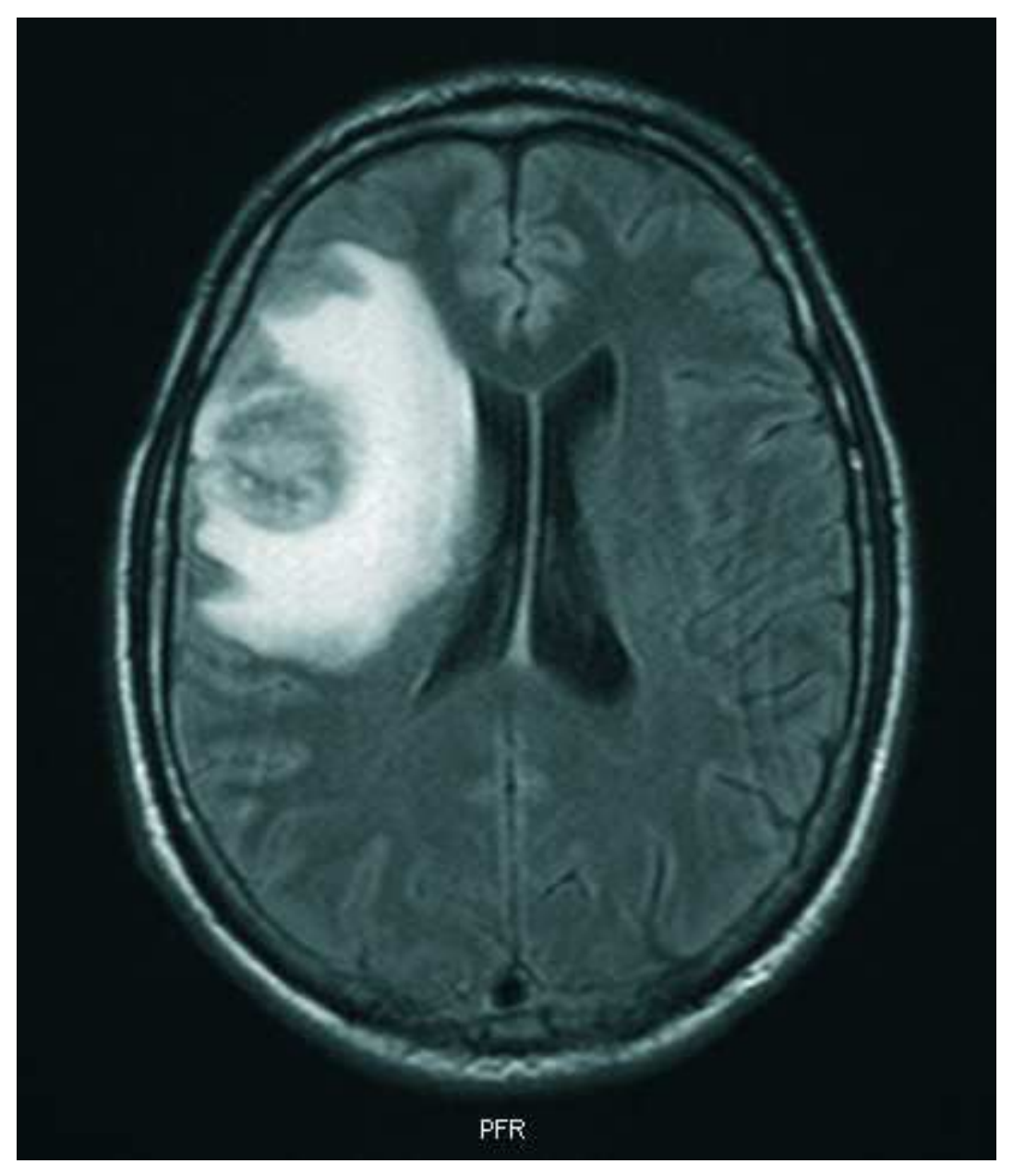

$34 \times 40 \mathrm{~mm}(300 \times 300$ DPI) 


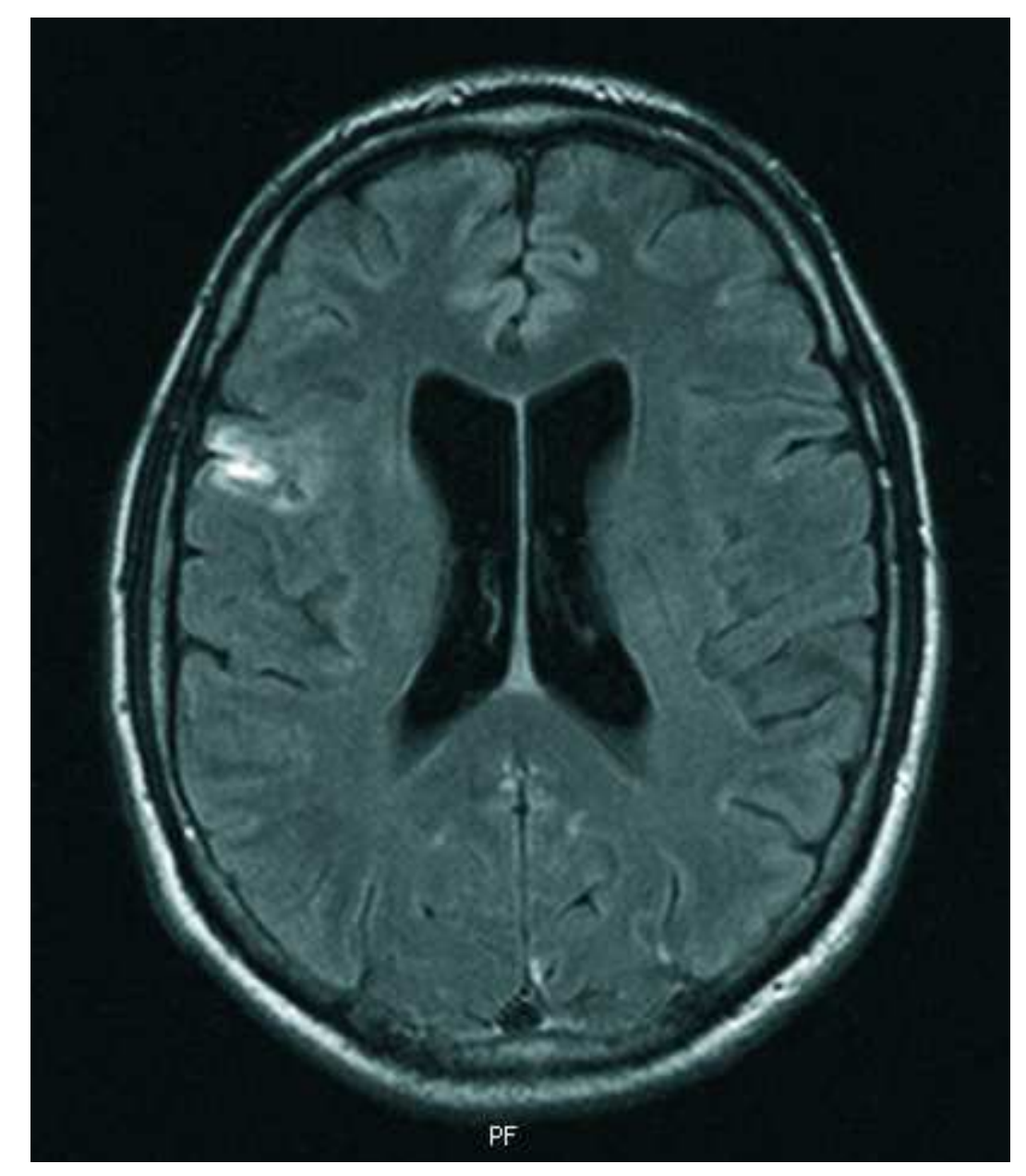

Fig. 1D

$34 \times 40 \mathrm{~mm}(300 \times 300$ DPI $)$ 


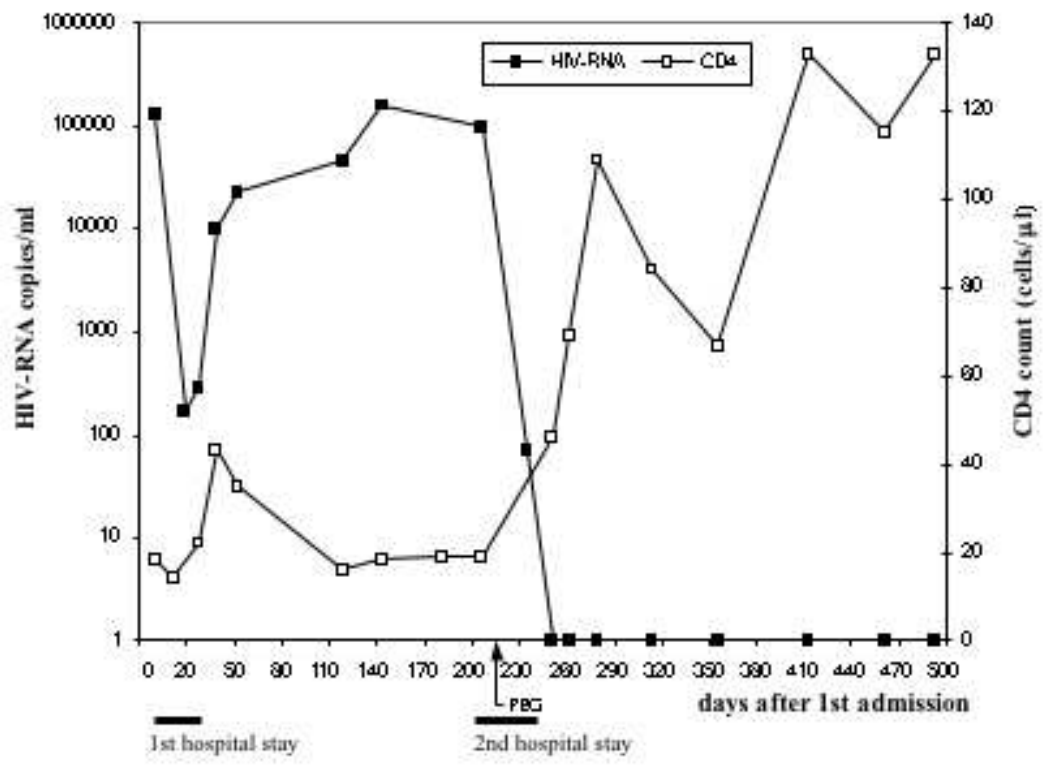

Fig. 2

$152 \times 116 \mathrm{~mm}(72 \times 72 \mathrm{DPI})$ 